\title{
THE AORTIC SYSTOLIC MURMUR DEVELOPING WITH INCREASING AGE
}

\author{
BY \\ D. L. BRUNS * AND L. G. VAN DER HAUWAERT $\dagger$ \\ From the Department of Medicine, Postgraduate Medical School of London
}

Received October 21, 1957

For a number of years increasing attention has been paid to the evaluation of systolic murmurs (White, 1927; Fahr, 1930; Bass et al., 1933; Shapiro, 1939; White et al., 1942; Baker et al., 1943; Levy et al., 1943; Sodeman, 1944; and Master, 1948). It has been found that they are common in patients without evidence of cardiac disease, and the importance of considering factors other than organic valvular stenosis and regurgitation has been stressed (Levine, 1933; Freeman and Levine, 1933; Friedlander and Brown, 1935; Stewart, 1951). Phonocardiographic studies have helped to identify those due to aortic stenosis (Evans, 1947; Leatham, 1951; Mannheimer, 1955; Aravanis and Luisada, 1957; and Wells, 1957).

While clinicians are well aware of the high incidence of systolic murmurs in persons past middle age, only a few studies have been devoted to them. A number of investigators have appreciated that the aortic valvular deformities, sometimes responsible for these murmurs, were not necessarily due to rheumatic valvulitis (Broadbent and Broadbent, 1897; Dumas et al., 1927; Friedberg and Sohval, 1939; Rednick, 1942; Evans, 1947). Others have emphasized the role of infundibular narrowing in the genesis of these murmurs (Gallavardin, 1924; Giraud and Bert, 1936).

The purpose of this paper is to give the incidence of aortic systolic murmurs, found in a hospital population aged 50 and over, and to analyse the clinical and pathological findings in such subjects.

\section{MATERIAL AND MethodS}

Three hundred patients over the age of 50 in the general medical wards of Hammersmith Hospital were examined (144 women and 156 men, average age 63.7 years). Well recognized valvular disorders of rheumatic, luetic, or congenital origin were excluded; but cases of ischæmic or hypertensive heart disease were included, if there was no evidence of severe congestive heart failure. Factors that may have modified the intensity of a murmur, such as hypertension, or anæmia, thyrotoxicosis or other high output states, were recorded. The patients could not be regarded as a sample representative of the healthy population of the same age, as most of them had a disabling illness and a number even some form of cardiovascular disease.

Special attention was paid to the pulse, blood pressure, the second heart sound, and the character of the murmur if present. The murmurs were classified into grades (Levine, 1933). To avoid any possible error, patients with very faint (grade 1) murmurs were included in the group without murmurs. Phonocardiographic tracings from the aortic and mitral areas were made in representative cases. Twenty-three of these 300 patients came to autopsy.

Concurrently a pathological examination was made of the heart in 168 subjects (male, 95 , and female, 73) reaching necropsy during the present study, excluding the same valvular disorders as in the clinical analysis. As well as the routine examination, special attention was paid to the

* Fellow of the U.S. National Foundation for Infantile Paralysis. $\uparrow$ British Council Scholar. 
presence or absence of thickening of the aortic valve, especially in the central part of the base of each cusp. If the cusps could be pressed flat against the aortic wall without any protuberance, the valve was recorded as normal. The valve thickening was considered slight, with a protuberance up to $3 \mathrm{~mm}$., moderate $3-5 \mathrm{~mm}$., and great over $5 \mathrm{~mm}$. Representative microscopic sections were made in selected cases. Dilatation of the aorta was recorded by measuring with a ruler the widest diameter of the ascending aorta and comparing it with the diameter of the aortic ring before fixation.

\section{RESULTS}

Clinical Study. Systolic murmurs were heard in 146 of the 300 cases studied. The incidence by decades is shown in Table I. The majority were best heard over the second right intercostal space but also in a band down the sternum, out towards the apex. The murmur was confined to the aortic area in 14 cases and to the apex in 22 . In the remaining 110 cases the murmur was heard in both areas, being loudest at the apex in 43 , at the aortic area in 39 , and of equal intensity in both areas in 28; 112 murmurs were of slight intensity (grade 2), and 34 were moderate to loud (grade 3 or over). The latter were often transmitted into the neck. A thrill was felt over the aortic area in only three cases. One loud murmur in the aortic area was musical. In nine cases, where there was a hyperkinetic circulation, a loud systolic murmur was well heard over the whole præcordium, including the pulmonary area, while in all the other patients the murmur was diminished in the latter area. The murmurs tended to be short, leaving an appreciable gap before the second heart sound. In only three cases was a soft pan-systolic murmur heard at the apex. Two of these patients had a recent myocardial infarction and one had severe hypertension. In addition, in one hypertensive patient an early diastolic murmur was heard at the left sternal border.

The second heart sound at the aortic area was loud in most patients, although normal in some others. Where splitting of the second heart sound was heard, it was not abnormally wide, except in the few patients with bundle-branch block.

Forty out of the 112 patients with a grade 2 murmur and 18 out of 34 with a murmur of grade 3 or over, had associated hypertension, anæmia (hæmoglobin $10 \mathrm{~g}$. or less), thyrotoxicosis, or liver failure due to cirrhosis.

TABLE I

INCIDENCE Of Murmurs in ReLATION to Age

\begin{tabular}{|c|c|c|c|c|}
\hline $\begin{array}{l}\text { Age } \\
\text { group }\end{array}$ & $\begin{array}{l}\text { Patients } \\
\text { studied }\end{array}$ & $\begin{array}{c}\text { Number with } \\
\text { murmurs }\end{array}$ & Grade 2 & $\begin{array}{l}\text { Grade } 3 \\
\text { or over }\end{array}$ \\
\hline $\begin{array}{l}50-59 \\
60-69 \\
70-79 \\
80-89\end{array}$ & $\begin{array}{r}115 \\
102 \\
70 \\
13\end{array}$ & $\begin{array}{r}43(37 \%) \\
48(47 \%) \\
46(66 \%) \\
9(69 \%)\end{array}$ & $\begin{array}{r}39 \\
36 \\
32 \\
5\end{array}$ & $\begin{array}{r}4 \\
12 \\
14 \\
4\end{array}$ \\
\hline Total .. & 300 & $146(49 \%)$ & $112(37 \%)$ & $34(11 \%)$ \\
\hline
\end{tabular}

\section{Phonocardiography}

Thirty-three phonocardiographic tracings were made from representative patients in different age groups and ætiological categories.

One case of recent myocardial infarction, mentioned previously, showed a soft pan-systolic murmur at the apex and a short ejection murmur at the aortic area. In 26 cases a "spindle"- or "diamond"-shaped murmur was shown, depending on the loudness (Fig. 1, 2, and 3). The point of maximal intensity, as measured over at least four cycles, coincided with the middle of systole in two cases (No. 4 and 25, on Fig. 1) and fell earlier in all the others. In seven cases, in which this pattern was not found, the murmur occupied the first half or two-thirds of systole. Hence, in all cases the clinical impression was confirmed that the murmur was short, relatively early in systole, 

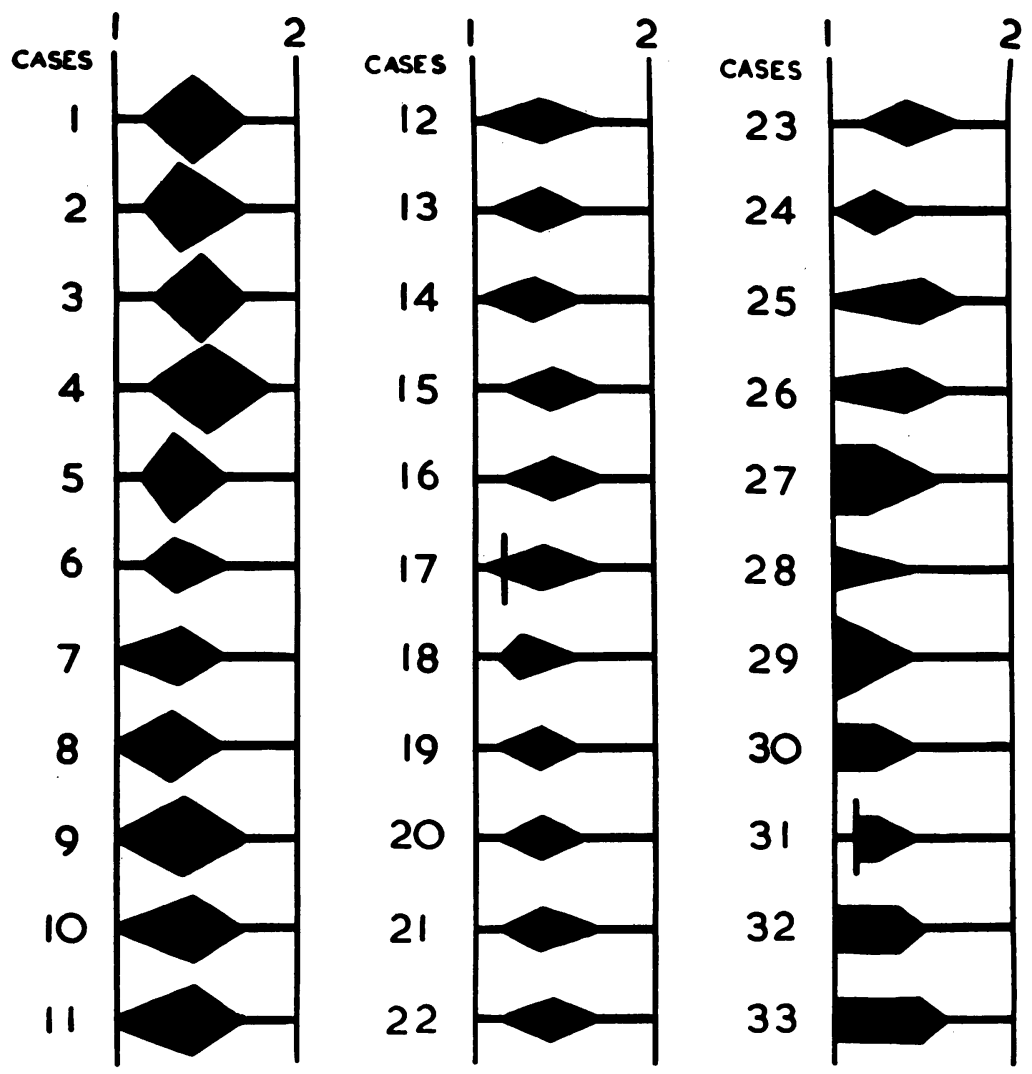

FIG. 1.-Diagrammatic representation of the systolic murmurs recorded in 33 patients over the age of 50 without evidence of aortic stenosis. The vertical line in Cases 17 and 31 represent a systolic click.

and ended an appreciable time before the second sound, which was often accentuated. No late systolic murmurs were recorded. The pattern of the murmur at the apex was indistinguishable from that at the aortic area, when it was audible in both positions. In 9 out of 10 cases, inhalation of amyl nitrite caused an intensification of the murmur without changing its position in systole. The murmur in hypertension and in hyperkinetic states was similar in all respects to those described. In three cases of atrial fibrillation the loudness of the murmurs varied with the duration of the preceding diastolic interval. On two occasions an early systolic click was recorded: the inhalation of amyl nitrite increased the intensity of the systolic click and shortened the interval between it and the first sound (Fig. 4).

Pathology. Some thickening of the cusps of the aortic valve was found in 120 of the 168 subjects coming to necropsy (of whom 23 were examined by the authors and included in the clinical study). This thickening appeared to originate in the aortic aspect of the base of the cusp (Fig. 5), so that the latter was less mobile and projected into the aortic lumen. In mild cases the thickening appeared to be fibrous and was confined to the central region of the cusp. With increasing severity, it spread towards the free margin and there was associated calcification (Fig. 6). In all cases the free margin of the valve was mobile and unaffected by this process. Fusion of the commissures was not seen; slight adhesions over a distance of 1 to $2 \mathrm{~mm}$. did not seem important, as they were just as frequent in normal valves without any thickening. Histological examination (Fig. 7) showed, in cases recorded as slight, some fibrous thickening in the proximal sixth of the fibrous lamina and of 


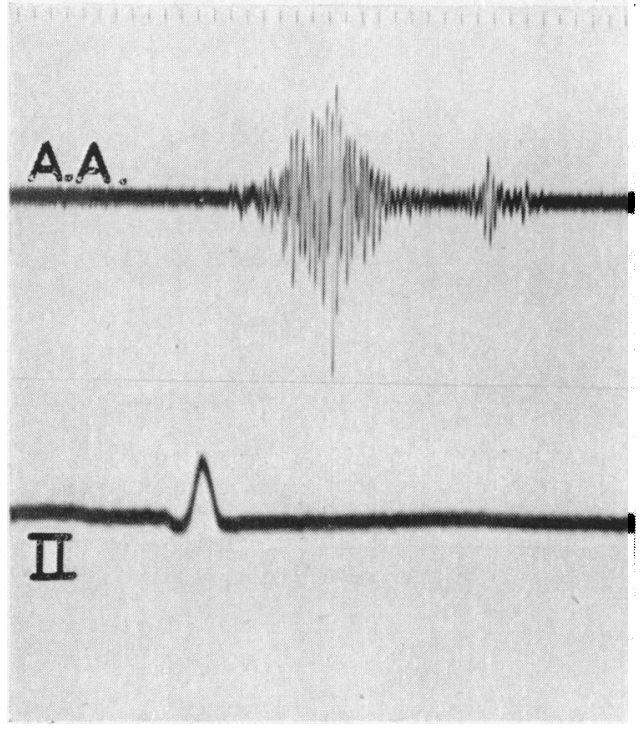

FIG. 2.-Diamond-shaped systolic murmur in the aortic area (A.A.) from a patient aged 67.

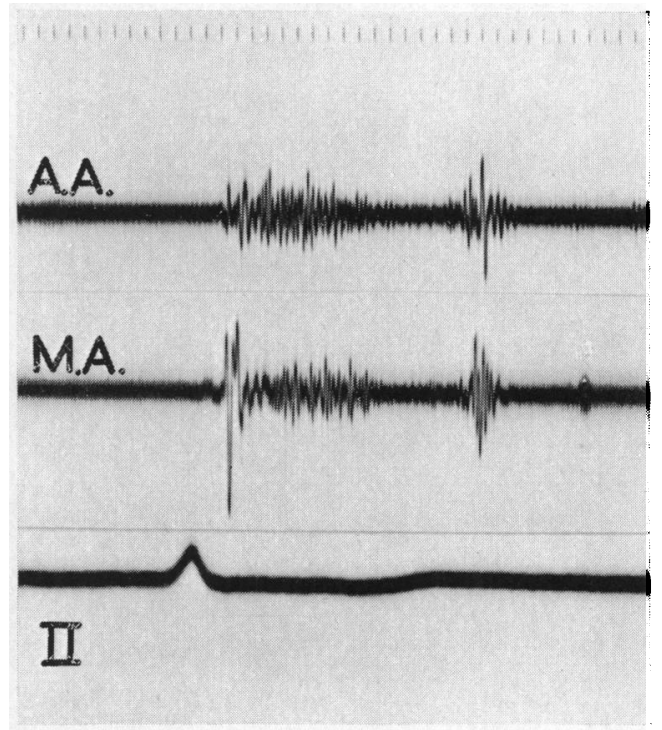

Fig. 3.-Spindle-shaped systolic murmur heard at the aortic and mitral area (A.A. and M.A.).

Time scale: One division $=0.02 \mathrm{sec}$. in Fig. 2 and 3.

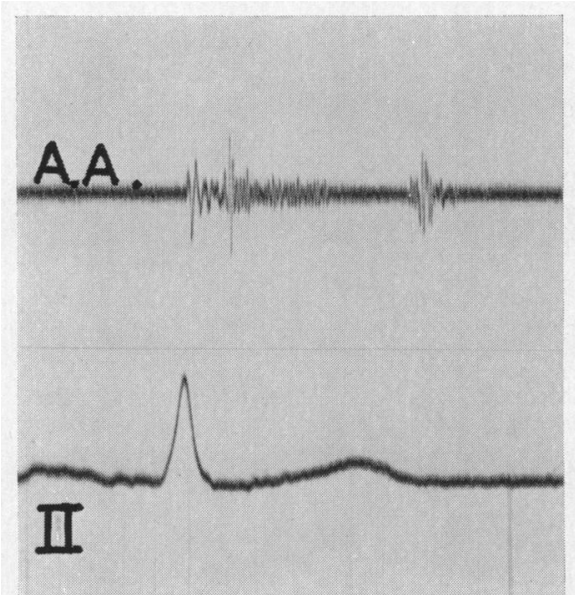

A

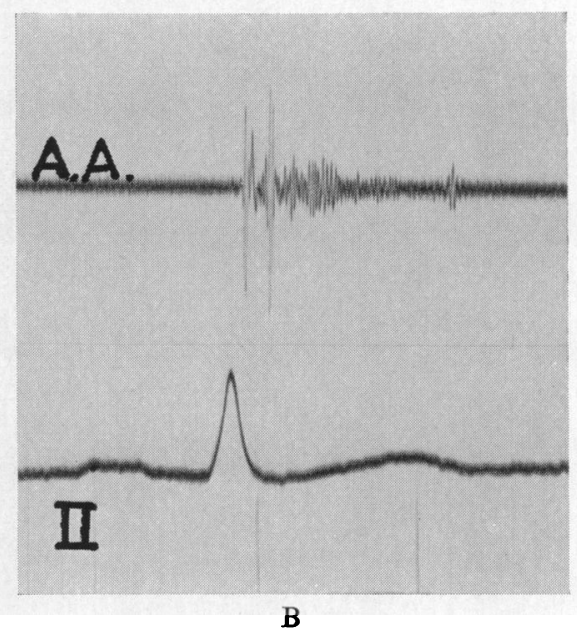

$B$

Fig. 4.-Systolic click and murmur in the aortic area, (A) before and (B) after inhalation of amyl nitrite.

the pocket at the point of attachment of the cusps. Moderate thickening was characterized by calcification within the fibrous lamina at the root of the cusps, with accompanying slight fibrous thickening, and great thickening by gross nodular calcification at the point of attachment of the cusps and the adjacent part of the fibrous lamina. Although the base of the valve projected into the aortic lumen, in no case was there severe obstruction to the passage of blood and the circumference of the most affected valve was still $6 \mathrm{~cm}$., which is only slightly less than the normal figure of 7 to $8 \mathrm{~cm}$. Figure 8 shows the relationship of this valve thickening to the age group, where there is a tendency for it to become more apparent with increasing years. The pulmonary valves remained entirely free from similar alterations throughout all the age-groups.

The ratio of the widest diameter of the ascending aorta to the diameter of the aortic ring 


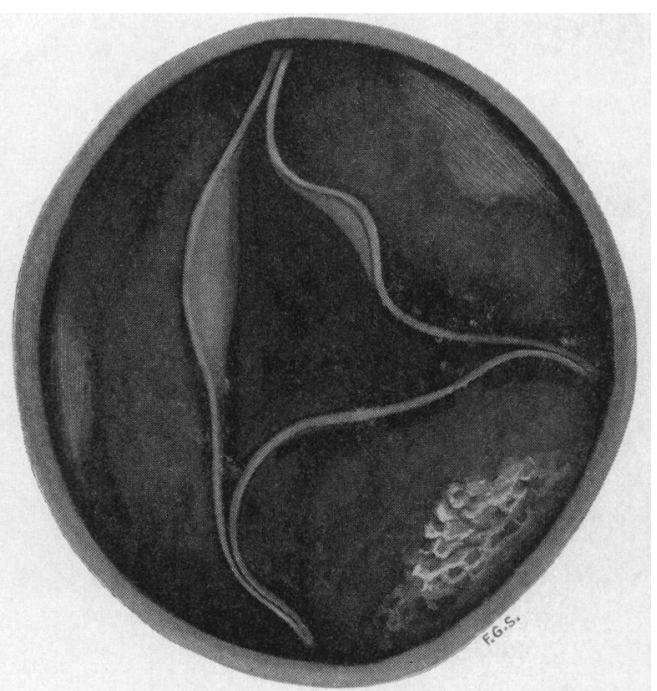

FIG. 5.-Diagrammatic representation of the aortic valve, showing the position and the mode of progression of the fibrous thickening and secondary calcification.

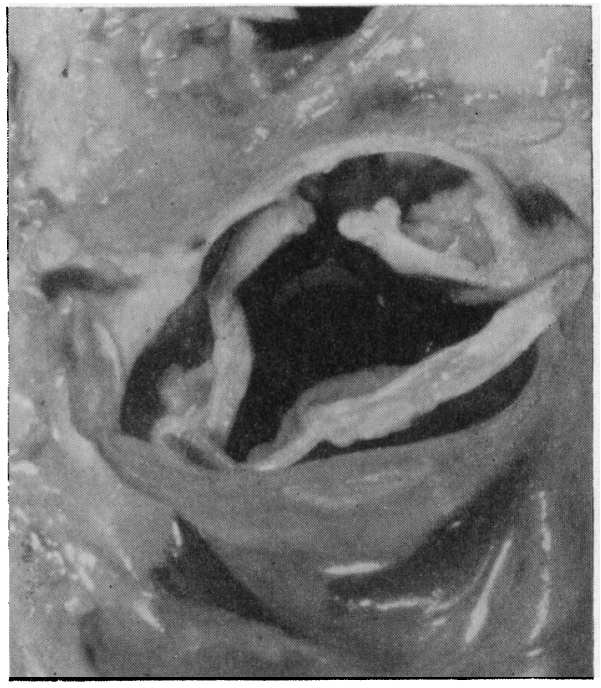

Fig. 6.-Calcified atheromatous nodules at the base of the valve, the leaflets of which are held open by a rubber tube.

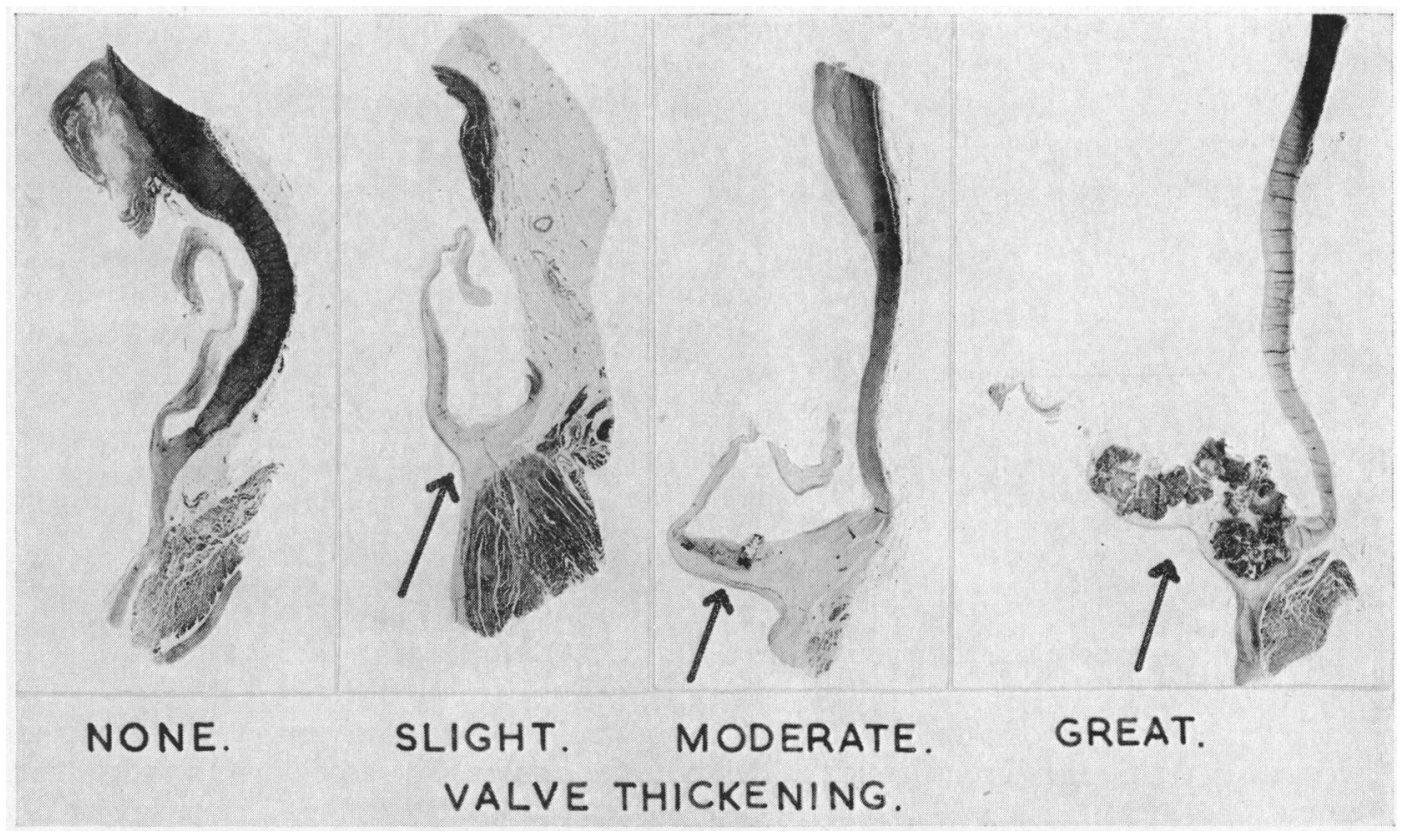

Fig. 7.-Histological sections of the aortic valve, showing different degrees of thickening at the base of the cusp.

increased from $0.94(0.80$ to 1.2$)$, in 35 cases under 50 years of age, to $1.14(0.93$ to 1.4$)$ in 100 cases older than this. Aneurysmal dilatation of the ascending aorta was not seen. We have intentionally avoided further statistical analysis of these data, as our simple method of measurement of the diameters would not permit any detailed conclusions. 


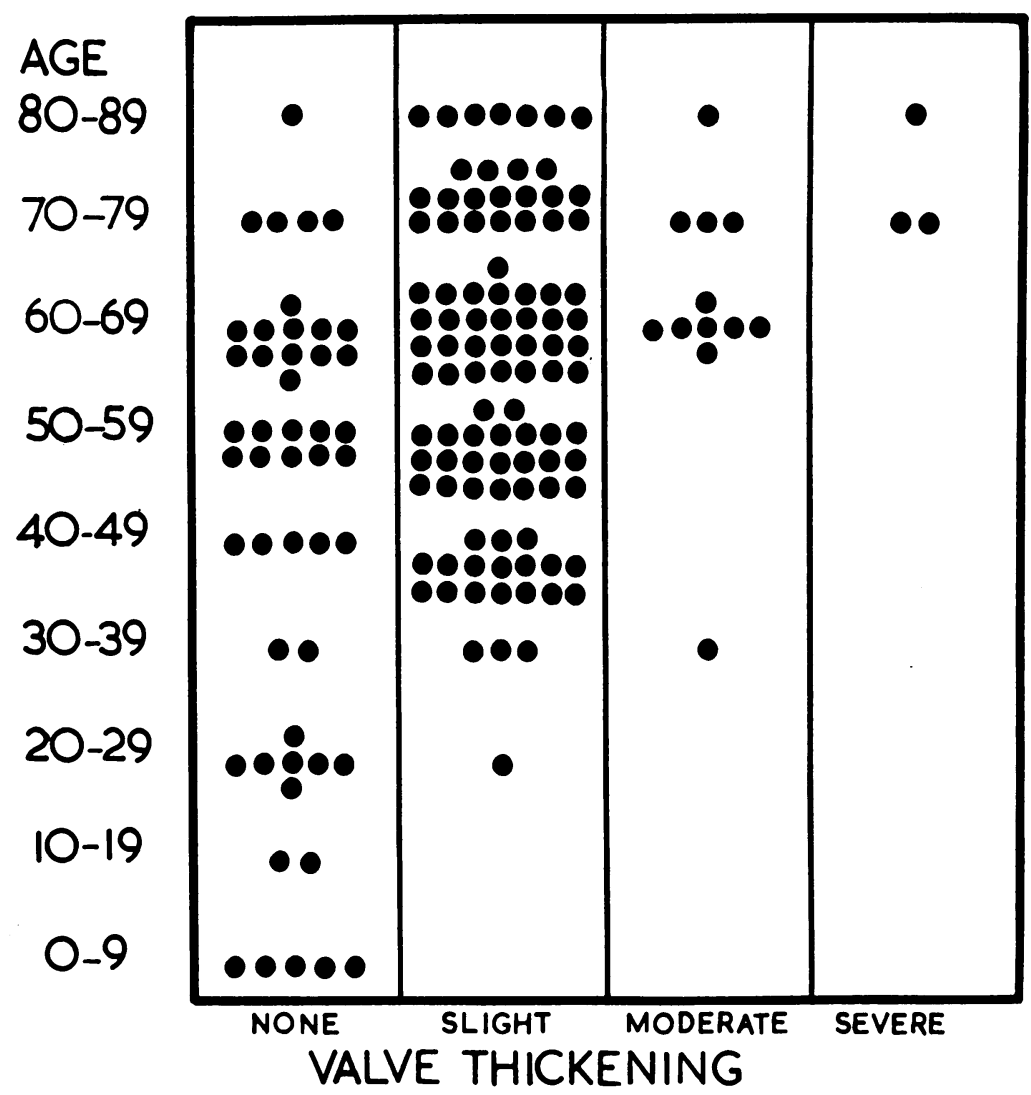

Fig. 8.-The relationship between the degree of valve thickening at necropsy and the age.

TABLE II

Correlation between the Clinical and Pathological Findings in 18 Cases without Hyperkinetic Circulation

\begin{tabular}{l|c|c|c|c}
\hline \multirow{2}{*}{$\begin{array}{c}\text { Intensity of the } \\
\text { murmur }\end{array}$} & \multicolumn{4}{|c}{ Valve thickenings } \\
\cline { 2 - 5 } & None & Slight & Moderate & Great \\
\hline $\begin{array}{l}\text { None } 2 \\
\text { Grade 2 }\end{array}$ & $\frac{4}{6}$ & 4 & 1 & - \\
Grade 3 or over & - & - & - & $\overline{2}$ \\
\hline
\end{tabular}

Correlation between clinical and pathological findings. Twenty-three patients, who had been studied in life by the authors, came to autopsy. As shown in Table II, there is a relationship between the intensity of the murmur and the degree of thickening of the aortic valve leaflets in 18 patients, who did not have a hyperkinetic circulation. Of the five cases with a hyperkinetic circulation, four had slight valve thickening, two of whom had a grade 2 , and two a grade 3 murmur.

\section{Discussion}

In contrast to childhood, where the right ventricular outflow tract seems to be the site of origin of most physiological murmurs (Bass et al., 1933; Friedlander and Brown, 1935; Sodeman, 1944; Mannheimer, 1955), the present study points towards the aortic valve as the origin of the great majority of murmurs heard in people over the age of 50 years. 
It must be emphasized that this series represents a general hospital population, in whom there were many patients with hypertension or with a hyperkinetic circulation. Therefore, it is likely that the incidence of these murmurs in the general population is less.

The pathological finding of thickening and even calcification of the base of the aortic valve leaflets is so common at necropsy, in the age groups over 50 , that one is inclined to consider at least the more advanced degrees as the explanation of an aortic systolic murmur with increasing age. These pathological changes are different from those of rheumatic origin in that the latter tend to be localized more in the free edges of the valves with associated distortion and fusion of the cusps. Since the original description by Mönckeberg (1904) others have confirmed that the incidence of calcification beginning in the base of the aortic valve leaflets is high and that many of these changes may be of atherosclerotic character (Sohval and Gross, 1936; Lesnick and Schlesinger, 1938; Hultgren, 1948; Boas et al., 1954). These authors, however, were mainly interested in the severe degrees of calcification leading to true calcific stenosis and did not stress the importance of considering lesser degrees of valvular changes in the production of murmurs in elderly people.

It appears from the present study that sclerotic lesions of old age, unless very advanced, do not usually produce a significant hæmodynamic obstruction and therefore tend to be benign, although they can cause a loud murmur. It is important to recognize the benign nature of such a murmur and not to label the patient as having serious heart disease, but rather to consider it as part of the natural ageing process. The murmur is exaggerated by increased speed of ejection through the slightly narrowed orifice and one would therefore expect it to be louder when the output of the heart is high, as in anæmia or thyrotoxicosis.

Clinically, the murmur of aortic valve sclerosis, when heard at the apex, may be differentiated from that due to mitral regurgitation, by its audibility in the aortic area, its transmission into the neck, its limitation to early or mid-systole, and its intensification by inhalation of amyl nitrite (Barlow and Shillingford, 1938). Differentiation has to be made from rheumatic aortic stenosis: the absence of a past history of heart disease and of other associated valvular lesions decreases the likelihood of a rheumatic origin in this age group. Furthermore, signs associated with obstructive aortic stenosis are nearly always lacking, such as left ventricular hypertrophy, alterations in the form of the pulse, and paradoxical splitting of the second sound. Phonocardiography showed that, while many rhomboid-shaped murmurs, similar to those seen in aortic stenosis (Leatham, 1951), were present, there was a significant difference, in that the point of maximal intensity fell almost invariably in the first half of systole. This is in agreement with the recent findings of Aravanis and Luisada (1957) who stated that 87 per cent of the murmurs in "relative aortic stenosis" were early diamond-shaped, whereas 67 per cent of cases with obstructing stenosis were late diamond-shaped. On the other hand, if one accepts the view that not all cases of aortic stenosis are rheumatic in origin, but that some of them are due to an arteriosclerotic process gradually developing from valve sclerosis to true obstruction, one should not be surprised to find borderline cases.

\section{SUMMARY}

The incidence of systolic murmurs has been studied in 300 hospital patients over the age of 50 . Clinical and phonocardiographic studies have shown that the majority arise in the aortic valve.

Aortic systolic murmurs become more frequent with increasing age: they can be loud especially in the presence of a hyperkinetic circulation.

The responsible pathological lesion in many cases appears to be the thickening of the base of the aortic valve cusps, which produces a murmur but does not obstruct significantly the outflow.

Addendum on the Mode of Production of Murmurs of Aortic Sclerosis

We were reluctant to accept these minor changes in the base of the aortic valve as a cause of the murmurs. Therefore we set up a series of tests in a model circulation, resembling the experiments of Bondi (1936). 
He described murmurs (audible eddies) produced in a continuously flowing stream of water, by various shapes of glass or brass tubes, at varying rates of flow. He did not study sounds produced by pulsatile flow. In view of the obvious importance of the pulsatile factor the Melrose artificial heart-lung machine was used in these experiments.

Brass tubes with varying types of narrowed lumen were placed in the outflow of the pump with the phonocardiograph-microphone $2 \mathrm{~cm}$. distal to the obstruction. The loudest murmurs were always obtained with tubes having an abrupt protrusion into their lumina. Figure 9 shows the type and intensity of murmurs recorded with a tapered narrowing and with an identical degree of narrowing produced by a diaphragm. In both cases the murmur is typically rhomboid-shaped but the diaphragm causes greater loudness and intensity for the same stroke-output. The ratio $(0 \cdot 125)$ of the protrusion to the lumen, in this example, is the same as that of a moderate pathological valve thickening $(3 \mathrm{~mm}$.) to the diameter of the aortic ring (24 mm.).

Thus even a slight but abrupt protuberance is capable of producing a murmur of considerable intensity, while a gradually changing diameter (such as dilatation of the ascending aorta) is less likely to produce an audible sound.

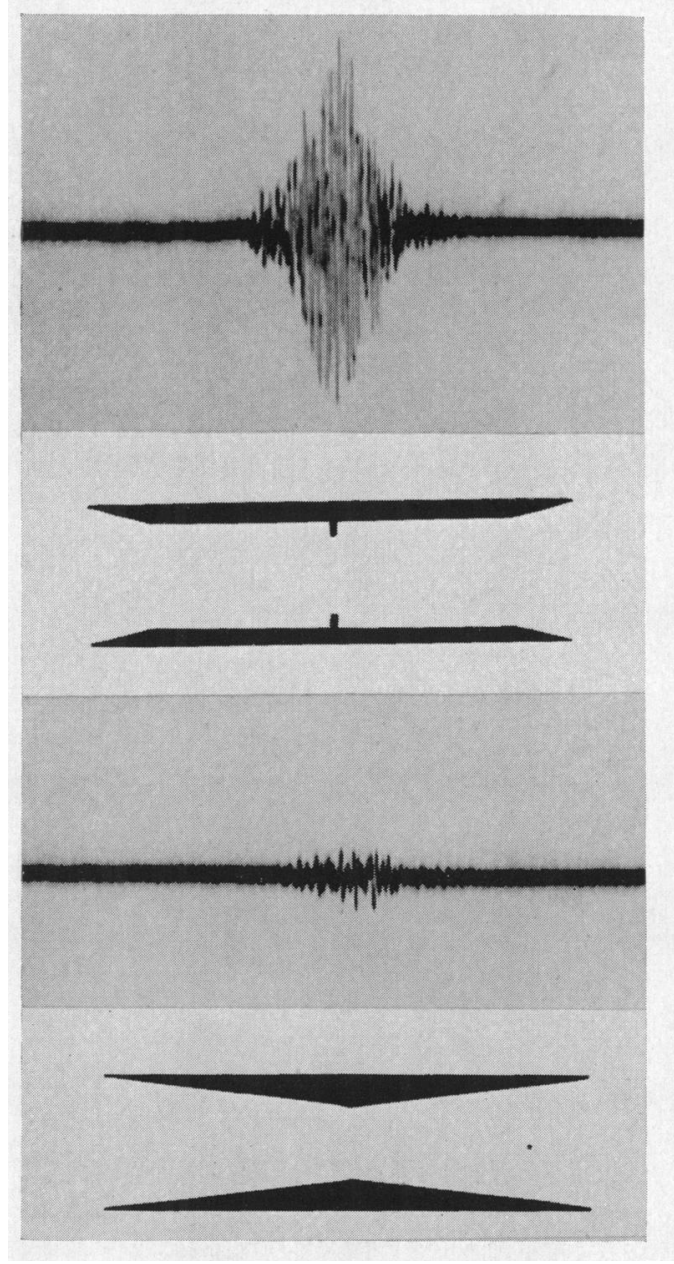

FIG. 9.--Murmurs recorded in model experiments by two brass tubes (seen in cross-section) with the same degree of stenosis but different internal configuration. The stroke-output of the pump and the sensitivity of the phonocardiograph were the same. 
We would like to express our thanks to Professor McMichael and Dr. Shillingford for the great interest they have shown in this study and for advice and assistance in the preparation of this paper. We also wish to thank Mr. C. Lordan for technical help.

\section{REFERENCES}

Aravanis, C., and Luisada, A. A. (1957). Amer. Heart J., 54, 32.

Baker, L. A., Sprague, H. B., and White, P. D. (1943). Amer. J. med. Sci., 206, 31.

Barlow, J. B., and Shillingford, J. (1958). Brit. Heart J., 20, 162.

Bass, M. H., Mond, H., Messeloff, C. R., and Oppenheimer, E. T. (1933). J. Amer. med. Ass., $101,17$.

Boas, E. P., Elster, S. K., and Adlersberg, D. (1954). Amer. Heart J., 48, 485.

Bondi, S. (1936). Ergebn. d. inn. Med., 50, 308.

Broadbent, W. H., and Broadbent, J. F. H. (1897). Heart Disease. Baillière, Tindall, \& Cox, London.

Dumas, A., Brunat, and Vernaud (1927). Lyon Méd., 140, 23.

Evans, W. (1947). Brit. Heart J., 9, 1 and 225.

Fahr, G. (1930). Nebraska med., J., 15, 458.

Freeman, A. R., and Levine, S. A. (1933). Ann. intern. Med., 6, 1371.

Friedberg, L. K., and Sohval, A. R. (1939). Amer. Heart J., 17, 452.

Friedlander, R. D., and Brown, M. G. (1935). Ann. intern. Med., 8, 893.

Gallavardin, M. L. (1924). Lyon Méd., 133, 33.

Giraud, G., and Bert, J. M. (1936). Arch. Mal. Coeur, 29, 613.

Hultgren, H. N. (1948). Arch. Path., 45, 694.

Leatham, A. (1951). Brit. Heart J., 13, 153.

Lesnick, G., and Schlesinger, M. J.'(1938). Amer. Heart J., 16, 43.

Levine, S. A. (1933). J. Amer. med. Ass., 101, 436.

Levy, R. L., Stroud, W. D., and White, P. D. (1943). J. Amer. med. Ass., 123, 937.

Mannheimer, E. (1955). Adv. Pediatr., 7, 171.

Master, A. M. (1948). Arch. intern. Med., 81, 518.

Mönckeberg, J. G. (1904). Virch. Arch. pathol. Anat. Physiol. Klin. Med., 172, 472.

Rednick, M. S. (1942). Ann. intern. Med., 16, 1197.

Shapiro, M. J. (1939). Amer. Heart J., 17, 416.

Sodeman, W. A. (1944). Amer. J. med. Sci., 208, 106.

Sohval, A. R., and Gross, L. (1936). Arch. Path., 22, 477.

Stewart, I. M'D. G. (1951). Brit. Heart J., 13, 561.

Wells, B. G. (1957). Brit. Heart J., 19, 129.

White, P. D. (1927). Amer. J. med. Sci., 174, 731.

-, Adams, F. D., and Craib, D. (1942). Amer. J. med. Sci., 203, 52. 